Research Article

\title{
Mapping QTLs for drought tolerance in a SEA 5 x AND 277 common bean cross with SSRs and SNP markers
}

Boris Briñez ${ }^{1}$, Juliana Morini Küpper Cardoso Perseguini ${ }^{1,2}$, Juliana Santa Rosa ${ }^{1}$, Denis Bassi ${ }^{1}$, João Guilherme Ribeiro Gonçalves ${ }^{3}$, Caléo Almeida ${ }^{1}$, Jean Fausto de Carvalho Paulino ${ }^{4}$, Matthew Ward Blair ${ }^{5}$, Alisson Fernando Chioratto ${ }^{3}$, Sérgio Augusto Morais Carbonell ${ }^{3}$, Paula Arielle Mendes Ribeiro Valdisser ${ }^{5}$, Rosana Pereira Vianello ${ }^{6}$ and Luciana Lasry Benchimol-Reis ${ }^{1}$

${ }^{1}$ Centro de Recursos Genéticos Vegetais, Instituto Agronômico (IAC), Campinas, SP, Brazil.

${ }^{2}$ Ciências Biológicas, Universidade Tecnológica Federal do Paraná (UTFPR), Dois Vizinhos, PR, Brazil.

${ }^{3}$ Centro de Grãos e Fibras, Instituto Agronômico (IAC), Campinas, SP, Brazil.

${ }^{4}$ Departamento de Agronomia, Universidade Estadual de Maringá (UEM), Maringá, PR, Brazil.

${ }^{5}$ Department of Agriculture and Natural Sciences, Tennessee State University, Nashville, TN, USA.

${ }^{6}$ Bean Program, Centro Nacional de Pesquisas Arroz e Feijão, Goiânia, GO, Brazil.

\begin{abstract}
The common bean is characterized by high sensitivity to drought and low productivity. Breeding for drought resistance in this species involves genes of different genetic groups. In this work, we used a SEA 5 x AND 277 cross to map quantitative trait loci associated with drought tolerance in order to assess the factors that determine the magnitude of drought response in common beans. A total of 438 polymorphic markers were used to genotype the F8 mapping population. Phenotyping was done in two greenhouses, one used to simulate drought and the other to simulate irrigated conditions. Fourteen traits associated with drought tolerance were measured to identify the quantitative trait loci (QTLs). The map was constructed with 331 markers that covered all 11 chromosomes and had a total length of $1515 \mathrm{cM}$. Twenty-two QTLs were discovered for chlorophyll, leaf and stem fresh biomass, leaf biomass dry weight, leaf temperature, number of pods per plant, number of seeds per plant, seed weight, days to flowering, dry pod weight and total yield under well-watered and drought (stress) conditions. All the QTLs detected under drought conditions showed positive effects of the SEA 5 allele. This study provides a better understanding of the genetic inheritance of drought tolerance in common bean.
\end{abstract}

Keywords: abiotic stress, interpopulation gene-pool, molecular markers, QTL mapping, water deficit.

Received: August 18, 2016; Accepted: April 3, 2017.

\section{Introduction}

The common bean (Phaseolus vulgaris L.) is an annual grain legume crop with important human consumption worldwide (Broughton et al., 2003). Drought stress is a serious agronomic problem that contributes to severe yield losses worldwide (Sabadin et al., 2012) and affects $60 \%$ of bean production, especially in Africa where this effect is particularly severe (Asfaw et al., 2013). Important bean producing areas that already suffer frequent droughts, such as Mexico, Central America, southern Africa and northeastern Brazil, are likely to receive even less average rainfall in the future because of climate change (Beebe et al., 2011).

Send correspondence to Juliana Morini Küpper Cardoso Perseguini. Ciências Biológicas, Universidade Tecnológica Federal do Paraná (UTFPR), 85660-000, PR, Dois Vizinhos, Brazil. E-mail: julianam@utfpr.edu.br
A broad understanding of the physiology of drought response is key to identifying useful selection criteria in addition to yield per se. The optimal plant response for dealing with moisture deficit will vary depending upon the pattern of drought (Cortés et al., 2013). Four patterns of drought have been defined: late initiation of rains, early cessation of rains or terminal drought, intermittent drought, or low rainfall throughout the season (Levitt, 1972).

Common beans of the Durango race germplasm (prostrate bush types with medium-sized seeds from the dry northern highlands of Mexico) reportedly possess the highest levels of drought resistance and have been used to develop drought resistant bean cultivars in the Middle American gene pool (Singh et al., 2001; Singh, 2007). According to Mukeshimana et al. (2014), combining the germplasm of the races Durango and Mesoamerica (smallseeded types, mostly bush habits, from lowland Central America and Mexico; Singh et al., 1991) has provided a 
consistent source of improved drought resistance for tropical environments. Singh et al. (2001) described the SEA 5 line as a drought tolerant cultivar derived from interracial crosses between the Mesoamerican and Durango races; one of the parents originating the SEA 5 line was the cultivar BAT 477.

Genetic and physiological mechanisms related to the responses of plants to water stress are important for the selection of more drought-tolerant plants. In general, drought resistance mechanisms include drought escape, drought avoidance and drought tolerance (Levitt, 1972). Drought escape allows plants to accelerate their cell cycle with early flowering and maturity, and rapidly relocates metabolites to seed production and away from leaves and shoots. Drought avoidance is the ability to maintain high tissue water potential through increased root depth, a reduction in hydraulic conductance, radiation absorption reduction in leaves, a reduction in water-loss area, reduced absorption of radiation by leaf movement, and reduced evaporation surface (leaf area). Drought tolerance is the ability of plants to resist the stress by adjusting cell osmosis, plasticity and size (Levitt, 1972).

Many traits influence tolerance to drought stress, including rooting pattern, the ability to partition a greater proportion of carbohydrates to seeds under stress, the capacity to set pods and fill seeds under stress, reduced stomatal conductance and leaf area, and the ability to maintain turgor through osmotic adjustment (Singh, 2007).

Breeding for drought tolerance is complex because of the number of traits involved, quantitative inheritance and environmental influence (Mir et al., 2012). A large amount of data has contributed to our understanding of the impact of drought on the common bean (Asfaw and Blair, 2012; Blair et al., 2012; Mukeshimana et al., 2014). However, the identification of major-effect QTLs with stable expression across different stress environments is needed to facilitate marker assisted selection (MAS) for drought tolerance in the common bean.

Molecular markers are powerful tools for analyzing the genetic control of complex traits such as drought tolerance (Mir et al., 2012). Asfaw and Blair (2012) used random amplified polymorphic DNA, amplified fragment length polymorphism and simple sequence repeats markers (SSRs) to map a Mesoamerican intra-gene pool cross of drought-susceptible DOR364 and drought-tolerant BAT 477, and detected a yield QTL on Pv08 and a stem carbohydrate QTL on Pv05.

Diversity analysis using intron-based SNPs revealed different patterns of diversity compared to that reported by Blair et al. (2009a,b) using SSRs. Mukeshimana et al. (2014) identified 14 QTLs for performance under drought in an inter-gene pool recombinant inbred line (RIL) population from a cross of the drought-tolerant line SEA 5 and CAL 96 cultivar; QTLs associated with yield components overlapped, especially on Pv03, Pv07, and Pv09. Villordo-
Pineda et al. (2016) observed 83 SNPs that were significantly associated with flowering time, physiological maturity, reproductive period, seed and total biomass, reuse index, seed yield, weight of 100 seeds, and harvest index in three cultivation cycles.

The goal of this study was to identify QTLs associated with physiological and yield components under drought and irrigation conditions based on an anchored linkage map obtained from a RIL population derived from a contrasting inter-gene pool cross between drought-tolerant (SEA 5 - Mesoamerican gene pool) and drought-susceptible (AND 277 - Andean gene pool) parents.

\section{Material and Methods}

\section{Plant material}

The population used in this study was a set of 107 recombinant inbred lines (RILs) from the cross SEA 5 x AND 277 created at the International Center for Tropical Agriculture (CIAT, Cali, Colombia). The population was propagated until the $\mathrm{F}_{8}$ generation using the single seed descent (SSD) method. The drought-tolerant dry bean line SEA 5 was also developed at CIAT (Singh et al., 2001; Terán and Singh, 2002) and is considered superior to BAT 477 (Pérez-Vega et al., 2011). SEA 5 was developed from the interracial double-cross population TR $7790=$ BAT 477/'San Cristobal 83'//'Guanajuato 31'/'Rio Tibagi'. BAT 477 is a cream-colored, small-seeded $(<25 \mathrm{~g} / 100$ seeds) breeding line developed at CIAT; BAT 477 has an indeterminate prostrate Type III growth habit and is highly tolerant to charcoal root rot [caused byMacrophomina phaseolina(Tassi) Goid]. San Cristobal 83 is a red mottled, small-seeded landrace with a Type III growth habit from the Dominican Republic. Guanajuato 31 is a beige-colored, medium-seeded (25-40 g/100 seeds) landrace of Type III growth habit from the semi-arid central highlands of Mexico. This line has high yields, a high harvest index and is resistant to anthracnose [caused by Colletotrichum lindemuthianum (Sacc. \& Magn.) Lams.-Scrib.]. Crosses involving Guanajuato 31 indicate that it possesses resistance genes to C. lindemuthianum races 6, 31, 38, 39 and 357 (Rodríguez-Soárez et al., 2007) and to race 83 (Alzate-Marin et al., 2009). Rio Tibagi has small black seeds and an indeterminate upright Type II growth habit; this is a popular cultivar in central and southern Brazil. BAT 477, San Cristobal 83 and Rio Tibagi belong to the Mesoamerica race, and Guanajuato 31 belongs to the Durango race. All four genotypes have some level of tolerance to drought, although Rio Tibagi has been classified as susceptible (Singh, 1995). AND 277 belongs to the Nueva Granada race and is of the Andean genepool (Blair et al., 2009a). This advanced line was derived from the complex cross [Cargabello x (Pompadour Checa x Línea 17) x (Línea 17 x Red Kloud)] and gamete selection. AND 277 is known to carry the $\mathrm{Co}^{-1}{ }^{4}$ (Arruda et al., 2008; Alzate-Marin et al., 
2003) and Phg-1 (Carvalho et al., 1998) genes that confer resistance to anthracnose (Colletotrichum lindemuthianum) and angular leaf spot (Pseudocercospora griseola) diseases, respectively, but is susceptible to drought.

\section{Phenotyping for drought tolerance}

The experiment was done from January to April 2012 at the Agronomic Institute (IAC, Campinas, SP, Brazil), located at $22^{\circ} 52^{\prime} 40^{\prime \prime}$ latitude south and $47^{\circ} 04^{\prime} 72^{\prime \prime}$ longitude west and an altitude of $685 \mathrm{~m}$. Two greenhouses were set up for the experiment. The first one (water stress) was covered with shade cloth as a sun screen and polyethylene plastic to prevent the entry of water during the experiment, while the second one (well water) was covered only with shade cloth.

Each greenhouse was filled with 428 plastic pots linked to an individual irrigation system that allowed control of the amount of incoming water and the drought stress generated in the experiment. The pots were filled with 12 $\mathrm{kg}$ of a soil, manure and sand mixture (in a 3:1:1 ratio). Since pot size can affect plant growth and performance (Pieruschka and Poorter, 2012), we used pots with a soil capacity of $12 \mathrm{~kg}$ to minimize the influence of pot size. The soil was adjusted to a neutral $\mathrm{pH}$ with lime and watered before filling the pots. The experimental design consisted of completely randomized blocks with four replicates. After one week of letting the soil settle, the pots were fertilized using chemically-formulated fertilizer (NPK 8-18-16) that was applied directly to the soil. The total amount of each nutrient was equivalent to $1.5 \mathrm{~g}$ of N, $6.0 \mathrm{~g}$ of $\mathrm{P}_{2} \mathrm{O}_{5}$ and 3.5 $\mathrm{g}$ of $\mathrm{K}_{2} \mathrm{O}$ per pot.

Soil moisture levels in the pots were measured with 30 watermark sensors (granular matrix sensors) that were randomly installed at soil depths of $20 \mathrm{~cm}$ in control and drought stress pots. Before planting, the seeds were rinsed for $1 \mathrm{~min}$ in $5 \%(\mathrm{v} / \mathrm{v}) \mathrm{NaClO}$, washed in distilled water and germinated in a Biological Oxygen Demand (BOD) incubator for $72 \mathrm{~h}$ at $25^{\circ} \mathrm{C}$. Three seeds of each genotype were planted per pot. During the growing season, irrigations were provided twice a day for a total volume of 400 $\mathrm{mL}$. Every two days, soil water tension was measured, along with the leaf temperature of the plants in the pots containing the sensors, as well as the ambient temperature and relative humidity of each environment. Days to flowering were recorded every day and the mean flowering date was calculated for each genotype.

After 20 days of water deficit, one plant of each genotype and each replication was collected for phenotypic analysis; the others were allowed to grow until the end of the crop cycle to measure yield. At this point, leaf temperature was measured with an infrared thermograph (Telatemp model AG-42D, Telatemp, CA, USA), after which the plants were cut at the soil surface and separated into leaves and stems. The chlorophyll present in the leaves was measured with a non-destructive, hand-held SPAD-502 chloro- phyll meter (Minolta Camera Co., Ltd., Japan). Leaf area was determined using a leaf area meter (LICOR model LI-3000). For these same plants, the fresh stem and leaf weights were measured using an analytical balance (BEL Engineering, Milan, Italy) to determine biomass partitioning. Plant parts were placed in separate paper bags and dried in an oven at $60^{\circ} \mathrm{C}$ for $48 \mathrm{~h}$ after which the stem and leaf biomass dry weights were determined.

The physiological and morphological responses to drought were measured 33 days after planting (DAP), when the water-stressed greenhouse plants reached a mean value of $160 \mathrm{kPa}$ of soil water potential. After the physiological and morphological evaluations, the remaining plants were evaluated at physiological maturity to determine their productivity. In general, the plants were harvested after approximately three months, at which point the number of pods at harvest, number of seeds per plant and number of seeds per pod were determined. In addition, yield and total seed weight and dry pod weight were estimated. The drought intensity index (DII) was calculated as $1-\frac{X d s}{X n s}$, where $\mathrm{Xds}$ and $\mathrm{Xns}$ are the mean seed yield of all genotypes under drought stress (ds) and no stress (ns) treatments.

\section{DNA extraction and genotyping}

DNA was extracted from $300 \mathrm{mg}$ of powdered lyophilized young leaves from the parents and all the RILs by the CTAB method. DNA concentration was measured in a NanoDrop 2000 (Thermo Scientific) and diluted in TrisEDTA (TE) buffer (10 mM Tris-HCl, $1 \mathrm{mM}$ EDTA, $\mathrm{pH}$ 8.0) to a final concentration of $50 \mathrm{ng} / \mu \mathrm{L}$ and stored at $4{ }^{\circ} \mathrm{C}$.

\section{Microsatellite amplification and analysis}

For microsatellite screening, 594 SSRs were tested for polymorphisms among the SEA 5 and AND 277 lines. These SSRs were previously published by Blair et al. (2006, 2008, 2009a), Benchimol et al. (2007), Hanai et al. (2007) and Campos et al. (2011). The amplification reactions included 30 ng of DNA, $1 \mathrm{U}$ of Taq DNA polymerase, $1.5 \mathrm{mM} \mathrm{MgCl}_{2}, 0.15 \mathrm{mM}$ of each dNTP, $0.8 \mathrm{pmol} / \mathrm{mL}$ of each primer (forward and reverse), $10 \mathrm{mM}$ Tris- $\mathrm{HCl}$ and $50 \mathrm{mM} \mathrm{KCl}$ in a final reaction volume of $15 \mu \mathrm{L}$. The following conditions were used for amplification: $1 \mathrm{~min}$ at 94 ${ }^{\circ} \mathrm{C}, 30$ cycles of $1 \mathrm{~min}$ at $94^{\circ} \mathrm{C}, 1 \mathrm{~min}$ at the specific annealing temperature for each SSR, and $1 \mathrm{~min}$ at $72^{\circ} \mathrm{C}$, with a final extension of $5 \mathrm{~min}$ at $72{ }^{\circ} \mathrm{C}$. The PCR products were visualized on a $3 \%$ agarose gel and stained with $1 \mathrm{X}$ GelRed (Biotium, Inc. Hayward, CA, USA). After checking the PCR amplification products, they were separated in a $6 \%$ denaturing polyacrylamide gel and visualized using silver staining. Molecular mass standards (10-bp and 100-bp ladders; Invitrogen) were included in the runs.

\section{Single nucleotide polymorphism (SNP) analysis}

Genotyping for the 384 SNPs was done using the Vera Code ${ }^{\circledR}$ BeadXpress platform (Illumina) at the Bio- 
technology Laboratory of Embrapa Arroz e Feijão (Goiania, GO, Brazil). A set of 384 SNP markers, validated through Prelim file (https://icom.illumina.com/Custom/UploadOpaPrelim/) previously identified for $P$. vulgaris (Müller et al., 2015) and derivatives of polymorphism between the lines BAT 477 of Mesoamerican origin and Jalo EEP558 of Andean origin were selected to compose the Oligo Pool Assay (OPA) SNP markers.

For the SNP detection procedure on the BeadXpress platform, three oligonucleotides were used, two allelespecific (ASO) primers for each of the variations of the same specific SNP locus and a third primer (LSO) binding to the 3' region fragment DNA containing the SNP target. After hybridization, the procedure consisted of extending the regions between the ASO and LSO, followed by melting from a ligase enzyme, thus forming a single allelespecific fragment. This fragment was subsequently amplified using the enzyme Titanium Taq DNA polymerase (Clontech Laboratories Inc., Palo Alto, CA, USA) and primers complementary to the ASO region were labeled with $\mathrm{Cy} 3$ and $\mathrm{Cy} 5$ fluorescence.

Finally, the PCR products were hybridized with the complementary region of LSO strings present on the surface of the holographic beads. SNP genotyping was done using the program Genome Studio version 1.8.4, (Illumina, USA), with call rate values ranging from 0.80 to 0.90 and $\geq$ 0.26 for GenTrain grouping of SNPs. Clustering (grouping) to call alleles for each SNP was done a priori in an automated manner based on the intensity of the signals from $\mathrm{Cy} 3$ and $\mathrm{Cy} 5$. These signals were grouped into three classes of genotypes representing homozygous (AA and $\mathrm{BB}$ ) and heterozygous $(\mathrm{AB})$ alleles. For data analysis, the groups were adjusted individually and manually by determining the best clusters based on the parental profile.

\section{Linkage mapping and QTL identification}

Segregation analyses the SNP and SSR scoring of the 105 recombinant inbred lines and the SEA 5 and AND 277 parents were done using the chi-square test $\left(X^{2}\right)$, assuming 1:1 segregation ratios, with Bonferroni corrections. The genetic map was constructed with OneMap software version 2.0-1 (Margarido et al., 2007) using the multipoint approaches and hidden Markov models for analysis in the RIL population. Briefly, after identifying the redundant markers and segregation distortion, the recombination fractions were estimated between each pair of markers using the two-point function. The markers were then assigned to the chromosomes using a LOD threshold of 3.0 and maximum genetic distance of $37.5 \mathrm{cM}$ in conjunction with the Kosambi (1944) map function and the make.seq function. For the remaining markers, the try.seq function was used.

The positioning of the markers was refined using make.seq and map functions consecutively. To help decide on the position of each marker inserted in a specific linkage group, the rf.graph.table and draw.try=TRUE function were used to display the heat map. The nomenclature of the chromosomes and physical positions were identified by comparisons through sequence similarity analysis using BLASTN against the $P$. vulgaris G19833 Andean genome (https://phytozome.jgi.doe.gov/pz/por-

tal.html\#! info?alias=Org_Pvulgaris) and the integrated genetic map for the common bean based on microsatellite mapping described by Blair et al. (2011) and Campos et al. (2011).

Normality of the phenotypic data of the least square means (LSMeans) distribution was assessed based on the skewness, kurtosis and Shapiro-Wilk values. The Box-Cox transformation was applied and the appropriate model for normalizing the data of each trait was selected using the lambda $(\lambda)$ parameter (Osborne, 2010).

Quantitative trait loci identification was done using QTL Cartographer v. 1.17 (Basten et al., 2005) with composite interval mapping (CIM) analysis. The likelihood ratio test (LRT) was used to check for the presence of QTL at $1 \mathrm{cM}$ walkspeed and $10 \mathrm{cM}$ window size. The coefficient of determination was calculated for each interval separately $\left(\mathrm{R}^{2}\right)$ and for each interval given the background markers $\left(\mathrm{TR}^{2}\right)$ to determine the phenotypic variance explained by a single QTL. LOD values were calculated using the formula LOD $=0.2172 *$ LRT. Multiple linear regression for each chromosomal position was applied at the $5 \%$ significance level to obtain the cofactors used in the analysis. Threshold values were identified for each trait based on 1000 permutations and represented by graphs using Excel 2010.

\section{Statistical analysis}

Analysis of variance (ANOVA) and the Generalized Linear Models (GLM) procedure were to assess the performances of the RILs and of each trait evaluated. All data and statistical analyses were done using the software SAS v.8.2 (SAS Institute, Cary, NC, USA). A value of $\mathrm{p}<0.05$ indicated significance.

\section{Results}

\section{Marker characteristics}

Among the 594 microsatellite markers screened in the parents, $150(25 \%)$ were polymorphic for the population and 80 SSRs (53\%) were mapped. SNP profiling produced 288 polymorphic markers, 251 of which were used in genetic mapping. The linkage map was constructed with a total of 331 markers that segregated among the population and covered all 11 bean chromosomes, with a total length of $1515.2 \mathrm{cM}$. All markers were distributed across the bean genome, with an average density of $4.5 \mathrm{cM}$. The size of the chromosomes ranged from $63.1 \mathrm{cM}(\mathrm{Pv} 10)$ to $221.2 \mathrm{cM}$ (Pv 1, Table 1). The highest saturation was found for $\mathrm{Pv} 3$, with 40 markers, including 30 SNPs and 10 SSRs. 
Table 1 - Distribution of SSRs and SNPs mapped in the 11 chromosomes of the common bean genetic map from the AND 277 x SEA 5 population.

\begin{tabular}{lccccc}
\hline Linkage group (Pv) & SSR & SNP & No. of linkage loci & Linkage length (cM) & Average distance (cM) \\
\hline 1 & 10 & 26 & 36 & 221.2 & 6.1 \\
2 & 11 & 21 & 32 & 161.4 & 5 \\
3 & 10 & 30 & 40 & 159.4 & 3.9 \\
4 & 5 & 18 & 23 & 128.4 & 5.5 \\
5 & 5 & 22 & 27 & 147.2 & 5.4 \\
6 & 8 & 19 & 27 & 148.3 & 5.4 \\
7 & 8 & 22 & 30 & 179.6 & 5.9 \\
8 & 7 & 22 & 29 & 86.7 & 2.9 \\
9 & 7 & 17 & 28 & 112.4 & 4.6 \\
10 & 5 & 23 & 35 & 63.1 & 2.2 \\
11 & 4 & 31 & 331 & 107.5 & 3 \\
Total & 80 & 251 & & 1515.2 & 4.5 \\
\hline
\end{tabular}

$\mathrm{cM}$ - CentiMorgan, SNP - single nucleotide polymorphism, SSR - simple sequence repeat.

\section{Field conditions}

The well-watered greenhouse or control treatment was kept at $80 \%$ field capacity throughout the experiment, with an average temperature of $34{ }^{\circ} \mathrm{C}$ and $52 \%$ relative humidity. The water-stressed greenhouse was under terminal stress conditions in the vegetative phase (V3/V4) and had an average temperature of $36.4{ }^{\circ} \mathrm{C}$ and relative humidity of $42.4 \%$. Humidity was lower in the stressed greenhouse and leaf temperatures showed almost the same pattern, with higher temperatures in the stressed greenhouse (Figure 1).

Descriptive statistics and analysis of variance of the morphological response patterns related to drought tolerance detected significant differences among the parents and RILs for most of the traits (Tables 2 and S1). In the wellwatered greenhouse, the parental lines, SEA 5 and AND 277 , differed in leaf dry biomass, leaf temperature, days to flowering, number of pods, number of seeds per pod, yield, number of seeds, seed weight and pod weight. Among the
RILs, all the traits were significant and showed a normal distribution (Figure S1). The two parents were similar in terms of chlorophyll, leaf area, leaf fresh biomass, stem fresh biomass and stem dry biomass. Heritability was lower for pod weight (0.28) and higher for leaf fresh biomass (0.93).

In contrast, in the water-stressed greenhouse, the parental lines differed in leaf area, leaf fresh biomass, leaf biomass, dry weight, leaf temperature, days to flowering, number of pods, number of seeds per pod, yield, number of seeds, seed weight and pod weight. Among the RILs, leaf fresh biomass and leaf biomass dry weight were not significant traits. Heritability was lower for leaf biomass dry weight (0.12) and higher for yield (0.95).

In the well-watered treatment, the mean yield of all the genotypes was $2.84 \mathrm{~g} /$ plant, and $1.97 \mathrm{~g} /$ plant in the treatment under drought stress. This result showed a $30 \%$ reduction in grain yield due to drought, calculated using the
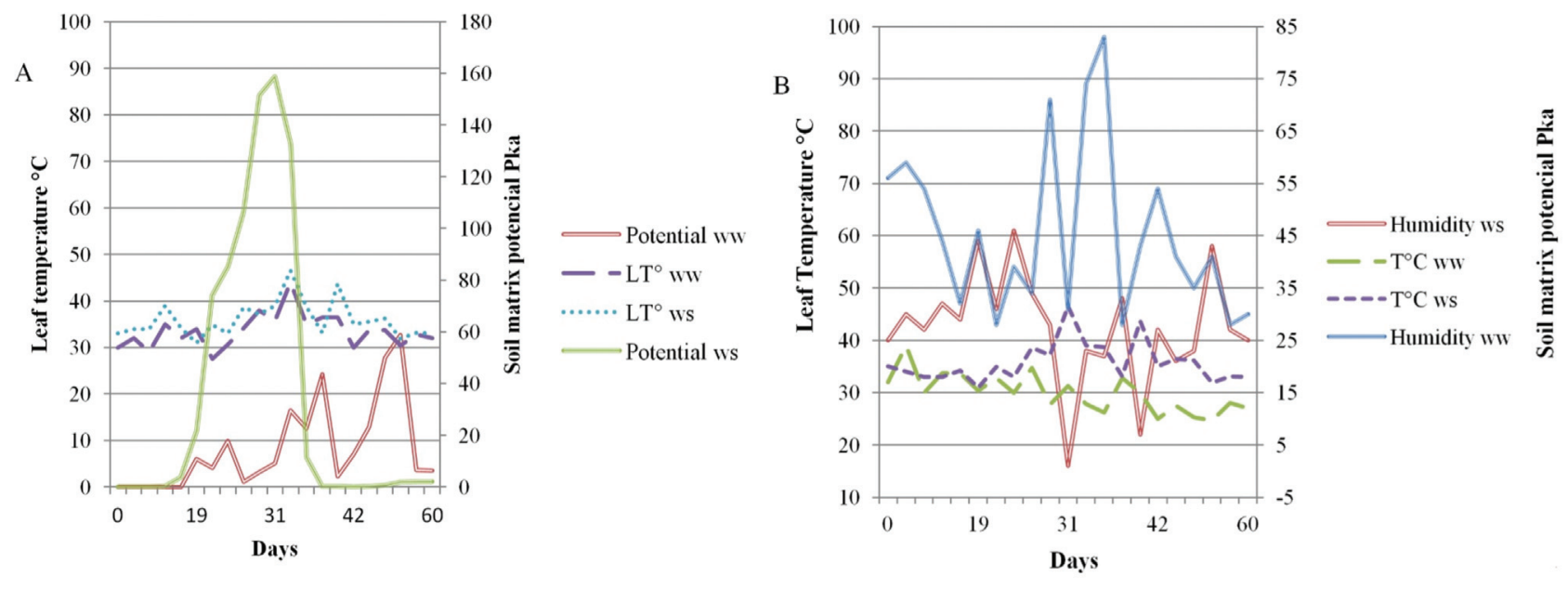

Figure 1 - Environmental parameters and soil matrix potential measured every two days during the first 60 days after planting. (A) Leaf temperature and soil water tension, (B) Greenhouse humidity and temperature. 
Table 2 - Analyses of variance for quantitative traits for AND 277, SEA 5 and recombinant inbred lines of the AS population evaluated in a greenhouse under irrigated and non-irrigated (water-stressed) conditions.

\begin{tabular}{|c|c|c|c|c|c|c|c|c|c|c|}
\hline \multirow[b]{3}{*}{ Trait } & \multicolumn{5}{|c|}{ Irrigated } & \multicolumn{5}{|c|}{ Non-irrigated } \\
\hline & \multicolumn{2}{|c|}{ Parents } & \multirow[b]{2}{*}{ Diff } & \multirow[b]{2}{*}{ Mean RILs } & \multirow[b]{2}{*}{$\mathrm{h}_{\mathrm{g}}^{2}$} & \multicolumn{2}{|c|}{ Parents } & \multirow[b]{2}{*}{ Diff } & \multirow[b]{2}{*}{ Mean RILs } & \multirow[b]{2}{*}{$\mathrm{h}_{\mathrm{g}}^{2}$} \\
\hline & SEA 5 & AND 277 & & & & SEA 5 & AND 277 & & & \\
\hline Chlorophyll & 42.46 & 43 & $\mathrm{~ns}$ & $41.69^{*}$ & 0.54 & 23.85 & 26.96 & $\mathrm{~ns}$ & $26.81 *$ & 0.71 \\
\hline Leaf area & 2098.7 & 2315.3 & $\mathrm{~ns}$ & $1402.59^{*}$ & 0.75 & 390.25 & 149 & $*$ & $303.96^{*}$ & 0.87 \\
\hline Fresh leaf biomass & 32.83 & 37.5 & ns & $26.59 *$ & 0.93 & 4.75 & 1.83 & $*$ & $3.17 \mathrm{~ns}$ & 0.21 \\
\hline Stem biomass fresh & 23.83 & 24.66 & ns & $17.07 *$ & 0.89 & 5.87 & 4.16 & ns & $4.92 *$ & 0.56 \\
\hline Dry leaf biomass & 4 & 6.83 & $*$ & $3.47^{*}$ & 0.64 & 1.87 & 1 & $*$ & $1.01 \mathrm{~ns}$ & 0.12 \\
\hline Dry stem biomass & 3.33 & 4.33 & $\mathrm{~ns}$ & $2.04 *$ & 0.36 & 1.25 & 1.5 & ns & $1.18^{*}$ & 0.39 \\
\hline Leaf temperature & 23 & 30.33 & $*$ & $28.25^{*}$ & 0.61 & 33.33 & 35.5 & $*$ & $34.63 *$ & 0.44 \\
\hline Days to flowering & 31 & 37.75 & $*$ & $36.77^{*}$ & 0.92 & 38 & 36 & $*$ & $36.37 *$ & 0.94 \\
\hline Number of pods & 13 & 5.25 & * & $10.56^{*}$ & 0.49 & 13 & 5 & $*$ & $14.53 *$ & 0.53 \\
\hline Number of seeds/pod & 4.23 & 2.32 & $*$ & $2.8^{*}$ & 0.64 & 4.5 & 2.7 & $*$ & $2.75^{*}$ & 0.73 \\
\hline Yield (g/plant) & 9.46 & 4.6 & $*$ & $6.67^{*}$ & 0.9 & 11.99 & 3.52 & $*$ & $7.74 *$ & 0.95 \\
\hline Number of seeds & 53.33 & 12.25 & $*$ & $27.79^{*}$ & 0.35 & 48 & 10.5 & $*$ & $37.65^{*}$ & 0.46 \\
\hline Seed weight ( $g / 100$ seeds) & 21.88 & 38.68 & $*$ & $22.02 *$ & 0.84 & 23.18 & 12.47 & $*$ & $23.89 *$ & 0.73 \\
\hline Pod weight & 4.14 & 1.14 & * & $2.28 *$ & 0.28 & 4.33 & 2.12 & $*$ & $3.87 *$ & 0.68 \\
\hline
\end{tabular}

Diff - difference between parents, $\mathrm{h}_{\mathrm{g}}^{2}$ - heritability. ${ }^{*} \mathrm{p}<0.05$; ns - not significant.

drought intensity index. Parental means were significantly different, except for leaf fresh and dry biomass.

\section{QTL mapping}

Of 22 QTLs identified in the experiment, eight were under drought conditions and 12 under irrigation conditions (Tables 3 and 4, Figure 2). Dry pod weight was detected only under drought treatment and explained $17 \%$ of the phenotypic variance with a negative allele for the QTL, indicating that SEA 5 contributed to this trait, with an LOD of 3.48 and a BAR3100 marker located within the QTL (Table 4). The QTLs were detected in both conditions but appeared on different chromosomes (Figure 2). The greatest amount of phenotypic variance associated with drought tolerance was detected for the chlorophyll QTL, with a coefficient of determination $\left(\mathrm{R}^{2}\right)$ of $32.8 \%$. However, this trait was also detected in the irrigated condition and explained $32.1 \%$ of the phenotypic variance. For drought treatment, stem fresh biomass, seed weight and number of seeds ( $\mathrm{g} / 100$ seeds) showed the greatest effects with $\mathrm{R}^{2}$ $(18 \%, 17 \%$ and $15 \%$, respectively). These QTLs were found linked to the BM159 marker in Pv 3, the BAR3474 marker in Pv 1 and the BAR3045 marker in Pv 7, with a contribution from the SEA 5 allele. All the QTLs detected under drought treatment showed a contribution from the SEA 5 parental allele, except for one chlorophyll QTL identified in Pv 11 and one QTL for leaf temperature identified in Pv 7. Fresh and dry biomass had a positive allele from AND 277 under irrigated treatment, whereas leaf temperature had a positive allele from AND 277 under both treatments. The number of pods and days to flowering un- der the irrigated treatment and the number of seeds and seed weight under both treatments had a negative allele from SEA 5. Positive and negative alleles contributed to yield in the irrigated treatment. Most of the QTL identified a contribution from SEA 5 (13) rather than from AND 277 (9).

\section{Discussion}

When compared to other maps (Campos et al., 2011; Blair et al., 2012; Oblessuc et al., 2014) the position of the markers remained the same on the 11 chromosomes, thus confirming the robustness and reliability of the genetic map generated by this study. The markers were placed on all 11 chromosomes and covered the whole genome, thereby allowing identification of the QTLs under two irrigation systems. The average genetic distance between markers was $4.5 \mathrm{cM}$ and therefore provides a dense map ideal for QTL analysis.

Exposure of the plants to drought stress substantially decreased the leaf water potential, relative water content and transpiration rate, with a concomitant increase in leaf temperature (Siddique et al., 2001). SEA 5 had cooler leaves than AND 277, apparently by reducing the leaf temperature in drought conditions (Table 2).

Three types of drought stress are commonly recognized, with two types of water supply (irrigated for nonstress and rain-fed for drought stress) being used to assess the effects of the intensity and duration of drought on crop growth and seed yield in genetically fixed materials (Blair et al., 2012; Sabadin et al., 2012). In this study, terminal drought stress was chosen because it affects over $60 \%$ of 


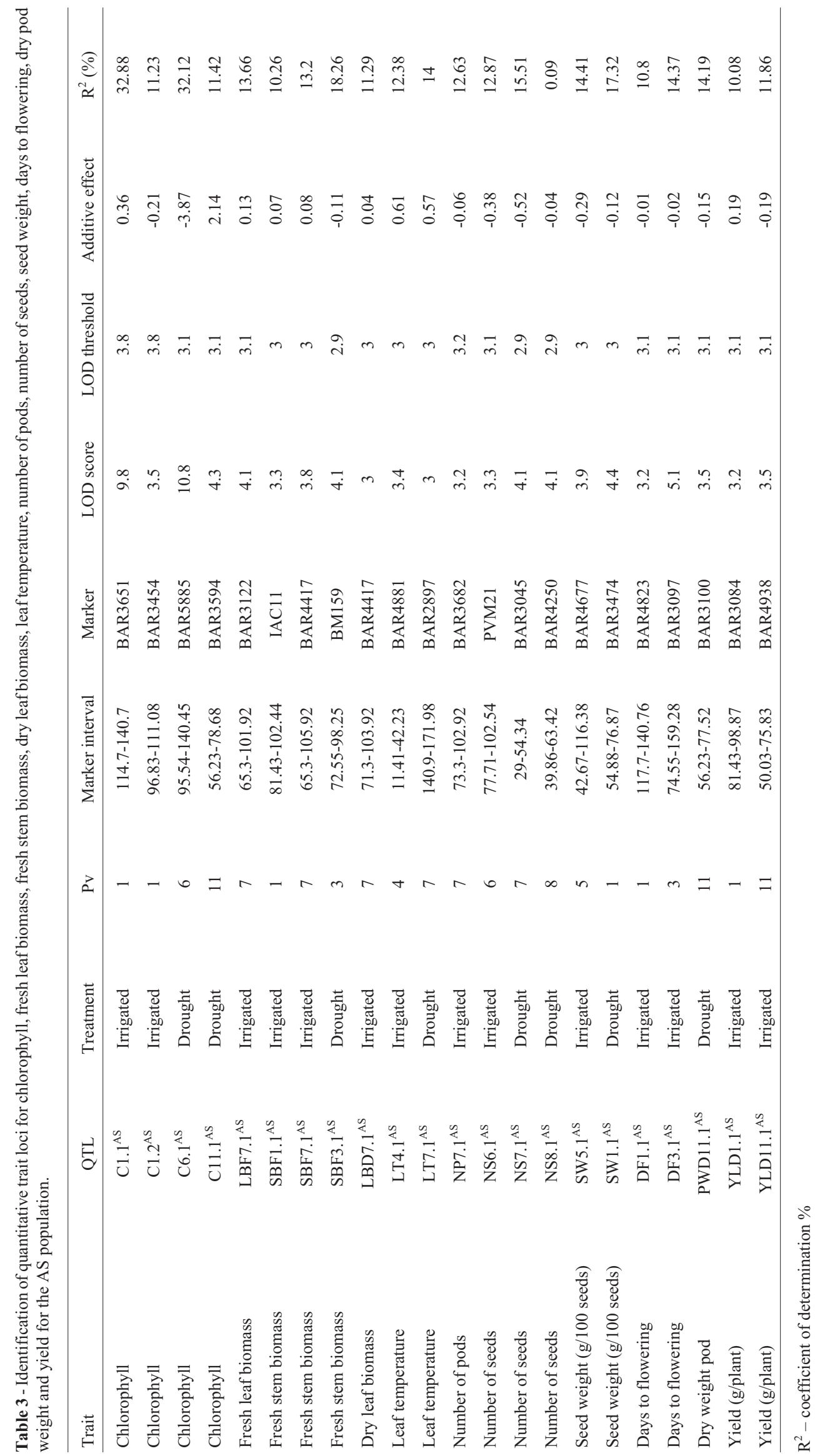


Table 4 - Identification of quantitative trait loci for significant drought tolerance in the AS population, their marker interval, marker located nearest to the QTL peak and its distance from the peak (in cM).

\begin{tabular}{|c|c|c|c|c|c|}
\hline Trait & Linkage group $(\mathrm{Pv})$ & Interval (cM) & Marker (distance to the peak) & $\mathrm{R}^{2}(\%)$ & Additive effect \\
\hline Chlorophyll & 6 & $95.54-140.45$ & BAR5885 (0 cM) & 32.1 & -3.87 \\
\hline Chlorophyll & 11 & $56.23-78.68$ & BAR3594 (0 cM) & 11.4 & 2.14 \\
\hline Fresh stem biomass & 3 & $72.55-98.25$ & BM 159 (2 cM) & 18.3 & -0.11 \\
\hline Leaf temperature & 7 & $140.9-171.98$ & BAR2897 (6 cM) & 14 & 0.57 \\
\hline Number of seeds & 7 & $29-54.34$ & BAR3045 (3 cM) & 15.5 & -0.52 \\
\hline Number of seeds & 8 & $39.86-63.42$ & BAR4250 (8 cM) & 0.09 & -0.04 \\
\hline Seed weight (g/100 seeds) & 1 & $54.88-76.87$ & BAR3474 (0 cM) & 17.3 & -0.12 \\
\hline Dry weight pod & 11 & $56.23-77.52$ & BAR3100 (0 cM) & 14.2 & -0.15 \\
\hline
\end{tabular}

$\mathrm{R}^{2}$ - coefficient of determination \%
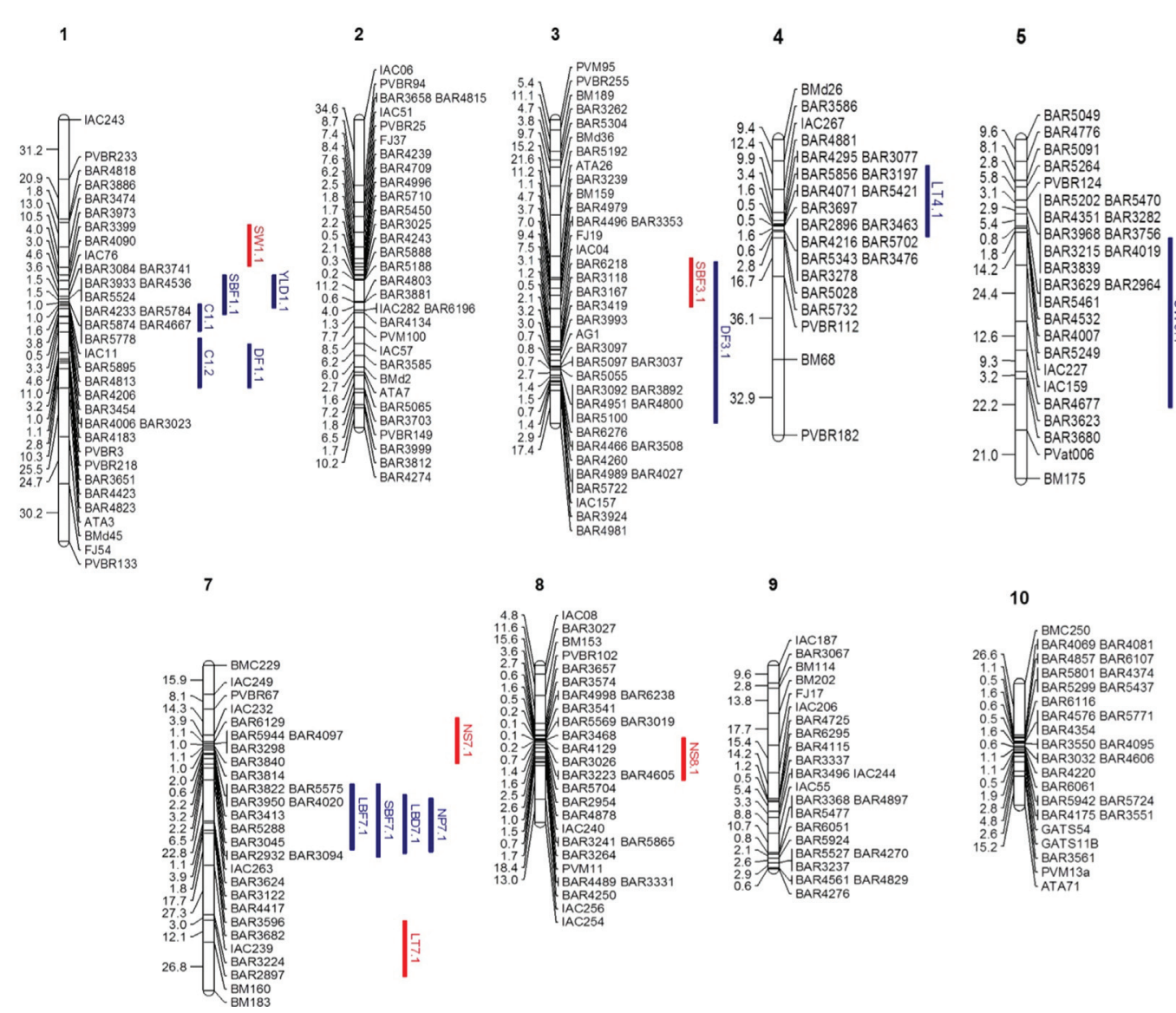
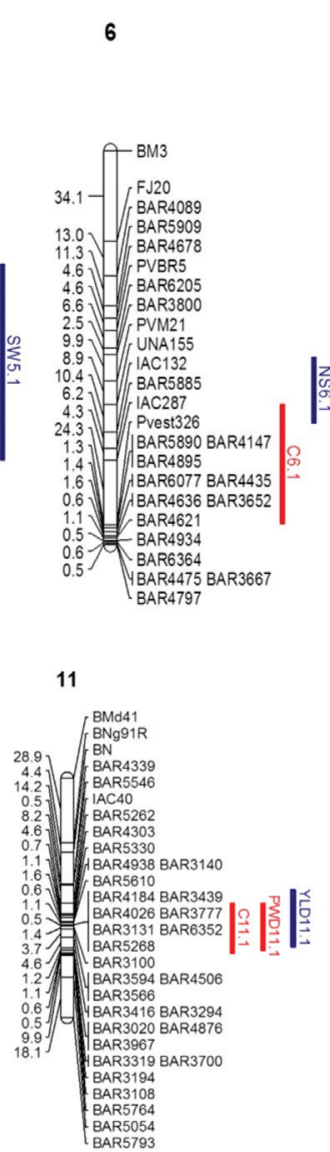

Figure 2 - Common bean linkage map constructed using the AND 277 x SEA 5 RIL population. The positions of the QTLs for drought (blue) and irrigated treatments (red) are shown. Chromosomes were assigned based on the P. vulgaris L. genome (http://www.phytozome.net/).

dry bean production worldwide (White and Singh, 1991), with the most affected areas in Latin America being northeastern Brazil and Central America. Although terminal drought stress is one of the most severe types of drought, the results of this experiment found a $30 \%$ reduction in grain yield and, surprisingly, even with the large reduction, some of the RILs had higher yields under terminal drought stressed conditions. These results corroborated those of Acosta-Diaz et al. (2004) and may be explained by the ob- servation that the drought allele (an allele for a favorable environment) was accompanied by a neutral allele for the other environment. This implies that yield under drought conditions and yield under well-watered conditions are not mutually exclusive and can be combined (Beebe et al., 2011). Analysis of variance of the quantitative traits showed that the SEA 5 parental line was significantly superior for almost all the traits measured under water stress conditions, except for leaf temperature. Under normal con- 
ditions, the days to flowering trait in SEA was greatly inferior to that of AND 277 under well-watered conditions and was greatly delayed under stress conditions (but was significant in both cases). The performance of SEA 5 with regard to the number of seeds/pod, yield, seed weight and pod weight was better under drought (stress) compared to wellwatered conditions, whereas the number of pods was unaffected.

Eight QTLs for drought conditions were identified and showed different levels of genetic variability; these QTLs were located on chromosomes 1, 3, 6, 7, 8 and 11. All the QTLs identified under drought conditions had the SEA 5 allele, except for the QTL for leaf temperature $\left(\mathrm{LT} 7.1^{\mathrm{AS}}\right.$ leaf temperature). Fourteen QTLs were identified in the irrigated environment, with $\mathrm{R}^{2}$ values ranging from $10 \%$ to $33 \%$, and were located on chromosomes 1, 3, 4, 5, 6, 7 and 11. QTLs were identified in all chromosomes except for chromosomes 2, 9 and 10. Overlapping QTLs were identified in chromosomes 1, 3, 6, 7 and 11. Blair et al. (2012) also found some overlapping QTLs and suggested that pleiotropic genes controlled two or more traits. Mukeshimana et al. (2014) found that correlated variables such as phenology, yield and yield components, co-localized on the same chromosome and that the yield QTL occurred mainly on Pv03 and Pv09. In the present study, leaf fresh biomass, stem fresh biomass, leaf biomass dry weight and the number of pods clustered together in Pv 7 under well-watered conditions. Although LBD7.1 ${ }^{\mathrm{AS}}$ (dry leaf biomass) showed a higher marker interval, it showed the same marker for the QTL peak (BAR4417) as SBF7.1 ${ }^{\text {AS }}$ (fresh stem biomass).

QTLs for chlorophyll, stem fresh biomass, leaf temperature, number of seeds and seed weight were identified in both treatments. For days to flowering, leaf fresh biomass, leaf biomass dry weight, number of pods and yield, QTLs were detected only in the irrigated treatment. For pod dry weight, a QTL was identified under drought conditions. The seed weight trait was important given that seed filling is inhibited under drought stress, so large seeds may indicate tolerance to drought and lead to higher yields (Ramírez-Vallejo and Kelly, 1998). Furthermore, the allele for seed size under drought and irrigated conditions came from the drought-tolerant parent, SEA 5. Two QTLs were found for seed weight, one in Pv 1 and the other in Pv 5. Blair et al. (2012) also found QTLs for seed weight in Pv 5 and Broughton et al. (2003) found QTLs in Pv 1. QTLs for days to flowering were found in $\mathrm{Pv} 1$ and 3, while Broughton et al. (2003) located them in $\mathrm{Pv} 1$ and 8. According to Mukeshimana et al. (2014), Pv03 also seems to be related to the seed weight QTL.

The nature of drought and its interaction with multiple environmental factors make the validation of QTLs much more complex. Schneider et al. (1997) studied the genetics of drought resistance using QTLs detected with RAPD markers. Four markers in one population and five in a second RIL population were reported to be important for drought resistance. Beebe et al. (2006) reported the identification of markers for QTLs under drought and irrigated conditions in a RIL population derived from the SEA $5 \mathrm{x}$ MD 23-24 cross; one QTL was common to two drought seasons, one was specific to each of two seasons, and some were common to unstressed environments. Blair et al. (2012) identified several QTLs in a BAT477 x DOR364 RIL, most of them being for seed weight followed by yield per day, yield per se, days to flowering and days to maturity. However, these authors noted that fewer QTLs were detected in the first year because of differences in the severity of drought stress and in the experimental conditions form year to year (terminal vs. intermittent drought).

In terms of breeding for drought tolerance, BAT 477 has been widely used to improve various classes of common beans (Terán and Singh, 2002). SEA 5 is an advanced line derived from BAT 477 that proved to have a superior background in terms of donor alleles favorable to QTLs associated with drought tolerance, as shown here. Mukeshimana et al. (2014) reported that the only QTL associated with yield under drought stress on Pv09 was contributed by the SEA 5 parent in combined environments, indicating the importance of SEA 5 alleles in maintaining yield under drought stress. Gonçalves et al. (2015) studied the combining ability under drought stress in common bean cultivars recommended for breeding programs aimed at drought tolerance, with grain yield as the parameter. Common beans of the Durango race, such as SEA 5 from the semi-arid highlands of Mexico, have been reported to have the highest levels of drought resistance (Terán and Singh, 2002). Thus, combining the germplasms of Durango and Mesoamerica races, such as SEA 5 x AND 277, may provide a consistent source of improved drought resistance for tropical environments (Mukeshimana et al., 2014).

Since the nature of drought and its interaction with multiple environmental factors makes QTL validation much more complex the challenge will be to test combined populations across broad classes of environments to determine which QTLs are stable. The complexity of this task will assist in rationally establishing an effective approach for marker-assisted selection (MAS). Beebe et al. (2013) suggested testing a subsample of 30-40 phenotypically extreme segregant RILs in a smaller trial over multiple sites for the sole purpose of validating the QTLs. Schneider et al. (1997) validated markers using a small set of selected RILs. Multiple environment trials should be done and QTL mapping confirmed in order to estimate genotype $\mathrm{x}$ environment $(\mathrm{G} \times \mathrm{E})$ interactions.

The results of this study indicate that SEA 5 and AND 277 parents had contrasting sensitivities to drought tolerance, with SEA 5 having a superior background in terms of donor alleles favorable to QTLs associated with drought tolerance. The SEA 5 genotype was superior for drought tolerance for traits such as leaf area, pod dry weight and yield. Genotyping with SSRs and SNPs showed a high level 
of polymorphism in the AS population and a high level of map saturation. Among QTLs associated with water deficit, $75 \%$ had a contribution from the SEA 5 genitor. For QTLs relevant to the cultivation of common beans, those related to leaf area, fresh mass and pod dry weight were the most important ones. Leaf foliar temperature was not a useful trait for future studies of QTLs associated with drought tolerance.

Drought tolerance is a complex quantitative trait controlled by many minor QTLs. This study confirmed that molecular markers are powerful tools for a better understanding of the molecular basis of drought tolerance in the common bean and, once validated, can be used in molecular breeding.

\section{Acknowledgments}

The authors thank CIAT (Cali, Colombia) for providing the seeds of the AS population. BB was the recipient of a fellowship from FAPESP (grant no. 2009/50275-0) and this work was supported by a research grant from FAPESP (grant no. 2010/51186-9).

\section{References}

Acosta-Díaz E, Trejo-López C, Ruiz-Posadas LM, Padilla-Ramírez JS and Acosta Gallegos JA (2004) Adaptation of common bean to drought stress during the reproductive stage. Terra Latinoamer 22:49-58.

Alzate-Marin AL, Arruda KM, Barros EG and Moreira MA (2003) Allelism studies for anthracnose resistance genes of common bean cultivar AND 277. In: Annual Report of the Bean Improvement Cooperative, Michigan. BIC 46:173174.

Alzate-Marin AL, Schuster I, Moreira MA and Barros EG (2009) Association of dominant and recessive genes confers anthracnose resistance in stem and leaves of common bean. $\mathrm{J}$ Phytopathol 157:70-72.

Arruda KMA, Alzate-Marin AL, Oliveira MSG, Barros EG and Moreira MA (2008) Inheritance studies for anthracnose resistance genes of common bean cultivar AND 277. Annual Report of the Bean Improvement Cooperative, Michigan. BIC 51:170-171.

Asfaw A and Blair MW (2012) Quantitative trait loci for rooting pattern traits of common beans grown under drought stress vs. non-stress conditions. Mol Breed 30:681-695.

Asfaw AA, Almekinders CJM, Struick PC and Blair MW (2013) Farmers' common bean variety and seed management in the face of drought and climate instability in southern Ethiopia. Sci Res Essays 8:1022-1037.

Basten CJ, Weir BS and Zeng ZB (2005) QTL Cartographer version 1.17: A Reference Manual and Tutorial for QTL Mapping. North Carolina State University, Raleigh.

Beebe SE, Rao IM, Blair MW, Tovar E, Grajales M and Cajiao C (2006) Identificación de QTL para resistencia a sequía en líneas recombinantes (RILs) de la cruza MD 23- 24 x SEA 5. Proceedings of the LII Annual Meeting of the PCCMCA (Program Cooperativo Centroamericano para el Mejoramiento de Cultivos y Animales), Montelimar, Nicaragua, pp. 24-28.
Beebe S, Ramírez J, Jarvis A, Rao IM, Mosquera G, Bueno JM and Blair MW (2011) Genetic improvement of common beans and the challenges of climate change. In: Yadav SS, Redden R, Hatfield JL, Lotze-Campen H and Hall A (eds) Crop Adaptation to Climate Change. Wiley-Blackwell, Oxford, pp 356-369.

Beebe SE, Rao IM, Blair MW and Acosta-Gallego JA (2013) Phenotyping of common beans for adaptation to drought. Front Physiol 4:1-19.

Benchimol LL, Campos T, Carbonell SAM, Colombo CA, Chioratto AF, Formighieri EF, Gouvêa LRL and de Souza AP (2007) Structure of genetic diversity among common bean (Phaseolus vulgaris L.) varieties of Mesoamerican and Andean origins using new developed microsatellite markers. Genet Resour Crop Evol 54:1747-1762.

Blair MW, Iriarte G and Beebe SE (2006) QTL analysis of yield traits in an advanced backcross population derived from a cultivated Andean $\mathrm{x}$ wild common bean (Phaseolus vulgaris L) cross. Theor Appl Genet 112:1149-1163.

Blair M, Buendia H, Giraldo M, Métais I and Peltier D (2008) Characterization of AT-rich microsatellite in common bean (Phaseolus vulgaris L.). Theor Appl Genet 118:91-103.

Blair MW, Torres MM, Giraldo MC and Pedraza F (2009a) Development and diversity of Andean-derived, gene-based microsatellites for common bean (Phaseolus vulgaris L.). BMC Plant Biol 9:100.

Blair MW, Diaz LM, Buendia HF and Duque MC (2009b) Genetic diversity, seed size associations and population structure of a core collection of common beans (Phaseolus vulgaris L.). Theor Appl Genet 119:955-972.

Blair MW, Hurtado N, Chavarro CM, Muñoz-Torres MC, Giraldo MC, Pedraza F, Tomkins J and Wing R (2011) Gene-based SSR markers for common bean (Phaseolus vulgaris L.) derived from root and leaf tissue ESTs: an integration of the BMc series. BMC Plant Biol 11:50.

Blair MW, Galeano CH, Tovar E, Torres MCM, Castrillón AV, Beebe SE and Rao IM (2012) Development of a Mesoamerican intra-genepool genetic map for quantitative trait loci detection in a drought tolerant susceptible common bean (Phaseolus vulgaris L.) cross. Mol Breed 29:71-88.

Broughton WJ, Hernandez G, Blair M, Beebe S, Gepts P and Vanderleyden J (2003) Beans (Phaseolus spp.) - model food legumes. Plant Soil 252:55-128.

Campos T, Oblessuc PR, Sforça DA, Cardoso JMK, Baroni RM, de Sousa ACB, Carbonel SAM, Chioratto AF, Garcia AAF, Rubiano LB, et al. (2011) Inheritance of growth habit detected by genetic linkage analysis using microsatellites in the common bean (Phaseolus vulgaris L.) Mol Breed 27:549-560.

Carvalho GA, Paula JT, Alzate-Marin AL, Nietsche S, Barros EG and Moreira MA (1998) Herança da resistência da linhagem AND-277 de Feijoeiro-Comum à raça 63-23 de Phaeoisariopsis griseola e identificação de marcador RAPD ligado ao gene de resistência. Fitopatol Bras 23:482-485.

Cortés AJ, Monserrate FA, Ramírez-Villegas J, Madriñán S and Blair MW (2013) Drought tolerance in wild plant populations: the case of common beans (Phaseolus vulgaris L.). PLoS One 8:e62898.

Gonçalves JGR, Chiorato AF, da Silva DA, Esteves JA de F, Bosetti F and Carbonell SAM (2015) Análise da capacidade 
combinatória em feijoeiro comum submetido ao déficit hídrico. Bragantia 74:149-155.

Hanai LR, Campos T, Camargo LEA, Benchimol LL, Souza AP, Melotto M, Carbonell SAM, Chioratto AF, Consoli L, Formighieri EF, et al. (2007) Development characterization and comparative analysis of polymorphism at common bean SSR loci isolated from genic and genomic sources. Genome 50:266-277.

Kosambi DD (1944) The estimation of map distances from recombinant values. Ann Eugen 12:172-175.

Levitt J (1972) Responses of Plants to Environmental Stresses. Academic Press, New York, 698 pp.

Margarido GRA, Souza AP and Garcia AAF (2007) OneMap: Software for genetic mapping in outcrossing species. Hereditas 144:78-79.

Mir RR, Zaman-Allah M, Sreenivasulu N, Trethowan R and Varshney RK (2012) Integrated genomics, physiology and breeding approaches for improving drought tolerance in crops. Theor Appl Genet 125:625-645.

Mukeshimana G, Butare L, Cregan PB, Blair MW and Kelly JD (2014) Quantitative trait loci associated with drought tolerance in common bean. Crop Sci 54:923-938.

Müller BSF, Pappas GJ, Valdisser PAMR, Coelho GRC, de Menezes IPP, Abreu AG, Borba TCO, Sakamoto T, Brondani C, Barros EG, et al. (2015) An operational SNP panel integrated to SSR markers for the assessment of genetic diversity and population structure of the common bean. Plant Mol Biol Rep 33:1697-1711.

Oblessuc PR, Baroni RM, Pereira GS, Chioratto AF, Carbonell SAM, Briñez B, Da Costa E, Silva L, Garcia AAF, Camargo LEA, et al. (2014) Quantitative analysis of race-specific resistance to Colletotrichum lindemuthianum in common bean. Mol Breed 34:1313-1329.

Osborne JW (2010) Improving your data transformations: Applying the Box-Cox transformation. Pract Assess Res Eval 15:9.

Pérez-Vega JC, Blair MW, Monserrate F and Ligarreto G (2011) Evaluation of an Andean common bean reference collection under drought stress. Agron Colomb 29:17-26.

Pieruschka R and Poorter H (2012) Phenotyping plants: genes, phenes and machines. Funct Plant Biol 39:813-820.

Ramirez-Vallejo P and Kelly JD (1998) Traits related to drought resistance in common bean. Euphytica 99:127-136.

Rodríguez-Soárez C, Mendes-Vigo B, Pañeda A, Ferreira JJ and Giraldez R (2007) A genetic linkage map of Phaseolus vulgaris $\mathrm{L}$. and localization of genes for specific resistance to six races of anthracnose (Colletotrichum lindemuthianum). Theor Appl Genet 114:713-722.

Sabadin PK, Malosetti M, Boer MP, Tardin FD, Santos FG, Guimarães CT, Gomide RL, Andrade CLT, Albuquerque PEP, Caniato FF, et al. (2012) Studying the genetic basis of drought tolerance in sorghum by managed stress trials and adjustments for phenological and plant height differences. Theor Appl Genet 124:389-402.

Schneider KA, Brothers ME and Kelly JF (1997) Marker-assisted selection to improve drought resistance in common bean. Crop Sci 37:51-60.

Siddique MRB, Hamid A and Islam MS (2001) Drought stress effects on water relations of wheat. Bot Bull Acad Sin 41:3539.

Singh SP (1995) Selection for water-stress tolerance in interracial populations of common bean. Crop Sci 35:118-124.

Singh SP (2007) Drought resistance in the race Durango dry bean landraces and cultivars. Agron J 99:1219-1225.

Singh SP, Gepts P and Debouck DG (1991) Races of common bean (Phaseolus vulgaris, Fabaceae). Econ Bot 45:379-396.

Singh SP, Teran H and Gutierrez JA (2001) Registration of SEA 5 and SEA 13 drought tolerant dry bean germplasm. Crop Sci 41:276-7.

Terán H and Singh SP (2002) Comparison of sources and lines selected for drought resistance in common bean. Crop Sci 42:64-70.

Villordo-Pineda E, González-Chavira MM, Giraldo-Carbajo P, Acosta-Gallegos JÁ and Caballero-Pérez J (2016) Identification of novel drought-tolerant-associated SNPs in common bean (Phaseolus vulgaris). Front Plant Sci 6:546.

White JW and Singh SP (1991) Sources and inheritance of earliness in tropically adapted indeterminate common bean. Euphytica 55:15-19.

\section{Supplementary material}

The following online, material is available for this article: Figure S1 - Distribution of quantitative traits across the RILs.

Table S1 - Descriptive statistics for the quantitative traits evaluated in the AND 277 x SEA 5 population.

\section{Associate Editor: Everaldo Gonçalves de Barros}

License information: This is an open-access article distributed under the terms of the Creative Commons Attribution License (type CC-BY), which permits unrestricted use, distribution and reproduction in any medium, provided the original article is properly cited. 